\title{
Care and Technology: Can they Connect?
}

\section{Carolyn L Lindgren*}

Doctors Hospital, Coral Gables FL, USA

With increasing technology the discussion continues about the increase in the depersonalization of the patient by health care professionals including nurses in light of the technological components that are a part of everyday health caredelivery whether at the bedside or other venues. Technology as a part of health care is not going to decrease but technology to monitor as well as facilitate treatment modalities will continue to escalate and be a significant part of future health care.

At the same time the need for patients to be viewed as individuals and human beings with values and unique characteristics cannot be ignored. Patients must be treated with respect, listened to and involved in the care modalities of their health regimen. Some take the view that caring manifested in listening, respect and building of rapport with the patient and technology are opposing forces. If the health care practitioner looks at all the computer screens that show the physiological state of the patient it is assumed by some that they have communicated with the patient and know that patient. But of course, those screens do not tell the whole story of the individual and all the factors that comprise that person's status of health. Even the demographics in the health record do not give a complete picture of that person. The electronic health record may have documented the person's height and weight and age and the conclusion that the person is overweight or underweight. However, this information tells nothing about the perspective of the individual concerning their weight, whether they understand their weight status and what it means to their health, whether they have any knowledge about nutrition or how their weight affects their esteem and psychological wellbeing. These issues have grave importance for this person in making any changes that would lead to a healthy weight and must be taken in consideration in planning and facilitating a care regimen for the patient.

Somehow, we must make the connection between the patient and the technology so they work together in an optimal way for quality health care. The individual characteristics of the human being cannot be left by the wayside. Their complexities must be embraced. Patient must know and feel they are a part of a caring relationship with the nurses and other health professionals who treat them as whole human beings who are partners in their care and worthy of care with dignity.

How can the connection between the interactive care of the nurse or health care professional be coupled with the technological advantages that contribute to the patient's treatment regimen? We need to look at the interactive processes with patients in a new light. The fundamental professional health care relationship is taught as a therapeutic relationship with buildup of rapport and resulting in problem solving for the patients. Now we must integrate technology into the fundamentals of that relationship. The human rapport between the patient and the nurse or other professional health care provider is not nullified by, but augmented with technological aspects that allow for more efficient problem solving for the patient. Each professional health provider has a responsibility to provide explanations to the patient about the technological recordings, assistive devices and electronic records and how they play a role in the care being given. Each practitioner has a responsibility to ensure they have a complete picture of the patient including the components that may not be recorded technologically. Even some of those aspects, such as perspective of the illness, degree of knowledge of their health state will eventually be more woven into the electronic picture of the patient as the electronic health recordings become more sophisticated. To provide patients with the best they deserve as individuals they must have the full use of the best technology that is available to facilitate their care. Health care professionals including nurses and their communication skills are a part of the link between the care of the patient who is understood and the technology that facilitates their care. Only putting care and utilizing the human relationship in concert with the technological data will result in increasing the quality of health care for the patient.
*Corresponding author: Carolyn Lindgren, Nursing Research Specialist, Doctors Hospital, Coral Gables FL, USA, Tel: 786-308-3240; Fax: 786-308-3303; E-mail: carolynl@baptisthealth.net

Received February 09, 2014; Accepted February 10, 2014; Published February 17,2014

Citation: Lindgren CL (2014) Care and Technology: Can they Connect? J Health Med Informat. 5: e126. doi:10.4172/2157-7420.1000e126

Copyright: $\odot 2014$ Lindgren CL. This is an open-access article distributed under the terms of the Creative Commons Attribution License, which permits unrestricted use, distribution, and reproduction in any medium, provided the original author and source are credited. 